\title{
PENGEMBANGAN SISTEM PENJUALAN BARANG ELEKTRONIK BERBASIS WEBSITE PADA PT. ELECTRONIC CITY INDONESIA
}

\author{
Zaenul Arifin ${ }^{1}$, Suranto Saputra ${ }^{2}$, Aswin Fitriansyah ${ }^{3}$ \\ Program Studi Teknik Informatika, Universitas Indraprasta PGRI \\ Jalan Raya Tengah No. 80, Kelurahan Gedong, Pasar Rebo, Jakarta Timur \\ zaenularifinn@gmail.com ${ }^{1}$, surantounindra@yahoo.co.id ${ }^{2}$, aswinf.und@gmail.com ${ }^{3}$
}

\begin{abstract}
Abstrak
Tujuan Penelitian ini adalah untuk mengetahui sistem penjualan barang elektronik yang sedang berjalan di PT. Electronic City Indonesia dan mengembangkan perancangan sistem penjualan barang elektronik untuk mengatasi kelemahan pada sistem sebelumnya. Metode penulisan yang digunakan dalam penelitian ini adalah metode Research and Development (R\&D) dan metode penelitian deskriptif kualitatif. Kesimpulan dari penelitian ini bahwa dengan adanya pengembangan sistem baru penjualan barang elektronik berupa fitur retur, pelanggan dapat dengan mudah untuk mengembalikan barang jika barang yang di beli tidak sesuai dengan yang diinginkan.
\end{abstract}

Kata Kunci: Sistem Penjualan Barang Elektronik, Website, PHP, MySql.

\begin{abstract}
The purpose of this research is to know the electronic goods sales system that is running at PT. Electronic City Indonesia and develop the design of electronic goods sales system to overcome the weaknesses in the previous system. The method of writing used in this research is the Research and Development $(R \& D)$ method and a descriptive method of kualitatiff. The conclusion of this research that with the development of new system of electronic sales in the form of return feature, customers can easily return the goods if the goods in the purchase does not match the desired.
\end{abstract}

Keyword: Systems Sales Electronic, Website, PHP, MySql.

\section{PENDAHULUAN}

E-Commerce merupakan proses transaksi jual beli yang dilakukan melalui situs internet dimana website digunakan sebagai wadah untuk melakukan proses bisnis yang menghubungkan antara perusahaan, konsumen dan komunikasi tertentu. Hal ini bisa atau dapat dilakukan melalui cara transaksi secara bersamaan atau sering kali disebut dengan istilah elektronik. Pengembangan sistem informasi penjualan merupakan hasil perkembangan teknologi sebuah aplikasi komputer yang nantinya diharapkan dapat membantu dan memudahkan pekerjaan manusia. Diharapkan pula sistem ini dapat membantu dalam kegitan sehari hari agar dapat efektif dan efisien. Pengembangan adalah suatu usaha untuk meningkatkan kemampuan teknis, teoritis, konseptual, dan moral sesuai dengan kebutuhan melalui pendidikan dan latihan (Majid, 2009). Sistem adalah sebagai kumpulan atau grup dari bagian atau komponen apapun baik fisik maupun non fisik yang saling berhubungan satu sama lain dan bekerja sama secara harmonis untuk mencapai satu tujuan tertentu.(Ahmad, 2013). Penjualan merupakan aktivitas memperjual belikan barang dan jasa kepada konsumen (Puspitawati, 2010). Penjualan adalah pendapatan yang berasal dari penjualan produk perusahaan, disajikan setelah dikurangi potongan penjualan dan retur penjualan (Sulistiyowati, 2010).

Berdasarkan dari permasalahan tersebut, maka ada beberapa solusi yang ditawarkan diantaranya masalah yang lebih spesifik agar proses penjualan barang elektronik dapat dilakukan secara maksimal. Pembatasan pengembangan sistem yang akan dibuat adalah sistem aplikasi yang akan dibangun menggunakan Bahasa pemrograman PHP dan database MySql di integrasikan dengan website yang sudah ada dengan perbaikan sistem baru. Perangkat lunak aplikasi adalah suatu subkelas perangkat lunak komputer yang memanfaatkan kemampuan komputer langsung untuk melakukan suatu tugas yang diinginkan pengguna.(H, 2012). PHP merupakan bahasa pemograman berbasis server - side yang dapat melakukan parsing script php menjadi script web sehingga dari sisi client menghasilkan suatu tampilan yang menarik.(YM Kusuma, 2012). MySQL merupakan RDBMS atau server database yang mengelola database dengan cepat menampung dalam jumlah sangat besar dan dapat di akses oleh banyak user (Raharjo, 2011). Dengan adanya pengembangan sistem diharapkan penjualan barang elektronik yaitu dengan adanya fitur retur customer dapat 
dengan mudah untuk mengembalikan barang jika barang yang di beli tidak sesuai dengan yang diinginkan.

\section{PENELITIAN RELEVAN}

Pengembangan Sistem Informasi Penjualan Berbasis Website Pada PT. Tiga Usaha Jaya Palembang, Peneliti Hendra Marta Aditamat, Tahun 2010,Fakultas Sistem Informasi STMIK GI MDP. Tujuan dari penelitian ini adalah membantu PT Tiga Usaha Jaya Palembang dalam mengembangkan konsep sistem e-Commerce yang mendukung layanan pada perusahaan, sehingga perusahaan mampu memberikan pelayanan yang maksimal kepada pelanggan guna meningkatkan nilai transaksi dan informasi produk kepada cutomer (pelanggan).

Peneliti Dony Febrian Syahputra, Judul Pengembangan Sistem Informasi Transaksi Penjualan Dan Komisi Agen Berbasis Web Pada PT. Akademi Pembicara Indonesia. Sumber Diunduh 15 November 2019 dari http://j-ptiik.ub.ac.id. Berdasarkan masalah yang diuraikan sebelumnya, dapat diberikan solusi untuk mengembangkan sistem informasi transaksi penjualan dan komisi agen. Hasil analisis kebutuhan divisualisasikan dalam use case diagram dan activity diagram. Hasil perancangan sistem menghasilkan sequence diagram, class diagram, relational data model, pseudocode algorithm, user interface. Implementasi dari sistem informasi ini menggunakan object oriented programming berupa aplikasi web.

Jurnal Vokasional Teknik Elektronika dan Informatika Vol. 6 No. 2 - Juli - Desember 2018 ISSN:2302 - 3295, Peneliti Muhamad Ghozi, Judul Pengembangan Sistem Informasi Manajemen Arsip Dan Disposisi Surat Berbasis Web Di BPN Kota Padang, Sumber diunduh 16 November 2019 dari http://ejournal.unp.ac.id/index.php/voteknika/index. Sistem informasi manajemen arsip dan disposisi ini dirancang dengan menggunakan metode prototyping berbasis web yang melibatkan pemrograman PHP bahasa (PHP Hypertext Preprocessor) berdasarkan framework codeigniter, JavaScript, Jquery. Selagi database yang digunakan adalah MYSQL. Dalam perancangan sistem terlibat Use Case, Activity Diagram, Context Diagram, Flowmap, Diagram Urutan dan ERD. Sistem ini juga menggunakan alias dalam mengatasi dengan menerapkan htaccess ke file alamat aktual sebagai salah satu sistem keamanan. Sistem informasi ini melibatkan lima pengguna tersebut sebagai admin, kepala urusan, kepala kantor, kepala seksi, dan kurir. Kelima level pengguna terdaftar ini memiliki akun pribadi untuk dapat memasuki sistem seperti nama pengguna dan kata sandi dengan MD5 enkripsi

\section{METODE PENELITIAN}

Dalam penelitian ini, peneliti melakukan pendekatan studi kasus dengan metode Research and Development (R\&D). Dalam pelaksanaan R\&D, ada beberapa metode yang di gunakan yaitu metode kualitatif dengan pendekatan deskriptif. Melalui metode tersebut bertujuan agar pengumpulan data yang di lakukan memperoleh data yang akurat.

Dalam penelitian ini, peneliti melakukan metode pengumpulan data untuk mendapatkan suatu data yang cukup dengan cara pengumpulan bahan-bahan keterangan dan data yang berhubungan dengan judul penelitian ini, sehingga tidak menyimpang dari pokok permasalahan. Adapun metode yang digunakan adalah:

Observasi yaitu metode untuk mendapatkan data dengan melakukan pengamatan langsung, pencatatan, dan pengumpulan data-data terhadap proses kerja sistem yang berjalan pada PT. Electronic City Indonesia.

Wawancara yaitu melakukan pengumpulan data dengan melakukan tanya jawab dan tinjauan kepada pegawai yang bertugas pada PT. Electronic City Indonesia mengenai hal yang berhubungan dengan penelitian ini.

Studi Pustaka yaitu metode pengumpulan data dengan cara mempelajari beberapa buku, sarana perpustakaan yang berhubungan dengan penelitian ini. 
Metode pengembangan sistem yang digunakan adalah metode Waterfall, dengan tahapan sebagai berikut :

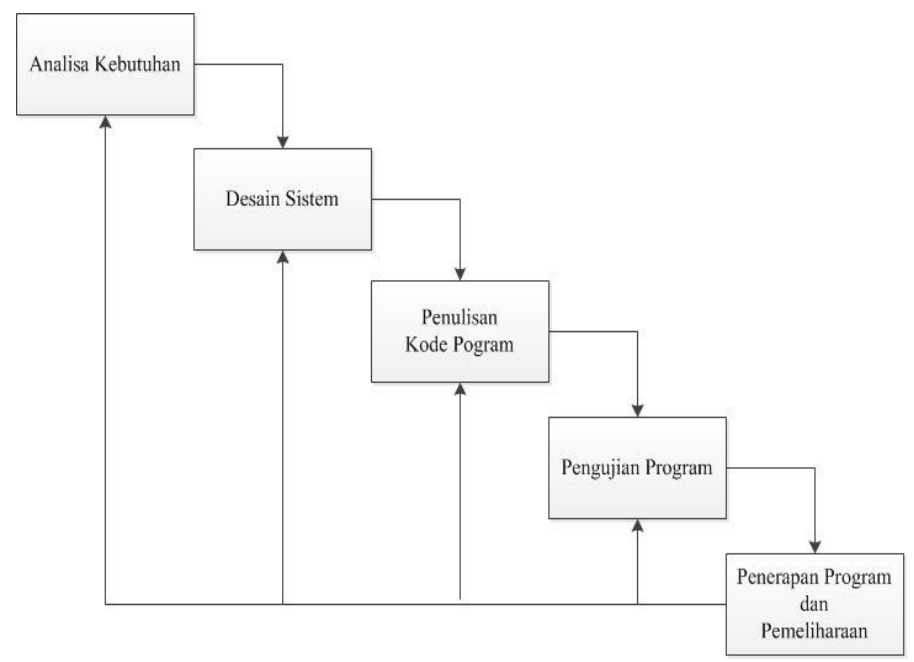

Gambar 1. Metode Waterfall

Sumber: (Pressman, 2015)

Berikut ini merupakan penjelasan dari langkah-langkah pengembangan sistem dengan metode waterfall:

Analisa Kebutuhan ini dibutuhkan untuk mengetahui apa saja yang dibutuhkan, bagaimana arus diagram aliran data dalam pembuatan sistem dan perancangan sistemnya, meliputi analisa aturan bisnis sistem, analisa masukan, diagram konteks, kamus data, normalisasi yang dilakukan, format masukan dan format keluaran.

Desain Sistem merupakan tahapan dimana dilakukan penuangan pikiran dan perancangan sistem terhadap solusi dari permasalahan yang ada dengan menggunakan perangkat permodelan sistem seperti diagram alir data (DAD), diagram hubungan entitas (ERD) serta struktur dan bahkan data. Penulisan kode program merupakan penerjemahan design dalam bahasa yang bisa dikenali oleh komputer. Dilakukan oleh programmer yang akan menterjemahkan transaksi yang diminta oleh user. Setelah pengkodean selesai maka akan dilakukan testing terhadap sistem yang telah dibuat tadi, Tujuannya adalah agar dapat memperbaiki program jika di temukan kesalahan pada sistem.

Pengujian Program adalah proses untuk memastikan apakah semua fungsi sistem bekerja dengan baik dan mencari apakah masih ada kesalahan pada sistem. Pengujian sangat penting dilakukan untuk menjamin kualitas software.

Penerapan Program dan Pemeliharaan Perangkat lunak yang sudah disampaikan kepada pelanggan pasti akan mengalami perubahan. Perubahan tersebut bisa karena mengalami kesalahan karena perangkat lunak harus menyesuaikan dengan lingkungan atau karena pelanggan membutuhkan perkembangan fungsional.

\section{HASIL DAN PEMBAHASAN}

Untuk mengatasi masalah tersebut, maka alternatif penyelesaiannya adalah dengan menambahkan fitur retur pada aplikasi agar konsumen dapat melakukan retur barang yang telah dibeli jika ada kerusakan dengan proses yang lebih mudah.

Aturan Bisnis Sistem yang Diusulkan:

1. Admin akan melakukan input data user jika ada penambahan user baru. Admin juga menambahkan daftar barang ke dalam database. Data barang akan di input oleh admin yang bertujuan untuk penambahan stok barang. Admin juga menambahkan data retur ke dalam database.

2. Customer melakukan login kedalam website sesuai dengan data form identitas yang telah dibuat sebelumnya, customer mencari barang yang ingin dibeli lalu menambahkan barang pembelian 
tersebut kedalam keranjang, jika barang yang ingin dibeli sudah masuk kedalam keranjang, maka customer melakukan checkout dan konfirmasi pembayaran.

3. Admin melakukan pembuatan laporan serta mencetaknya untuk diberikan kepada kepala toko setiap sebulan sekali. Baik itu laporan data barang, data customer, data purchase order, data konfirmasi, maupun data retur.

Berikut ini adalah Diagram Alir Data yang Diusulkan

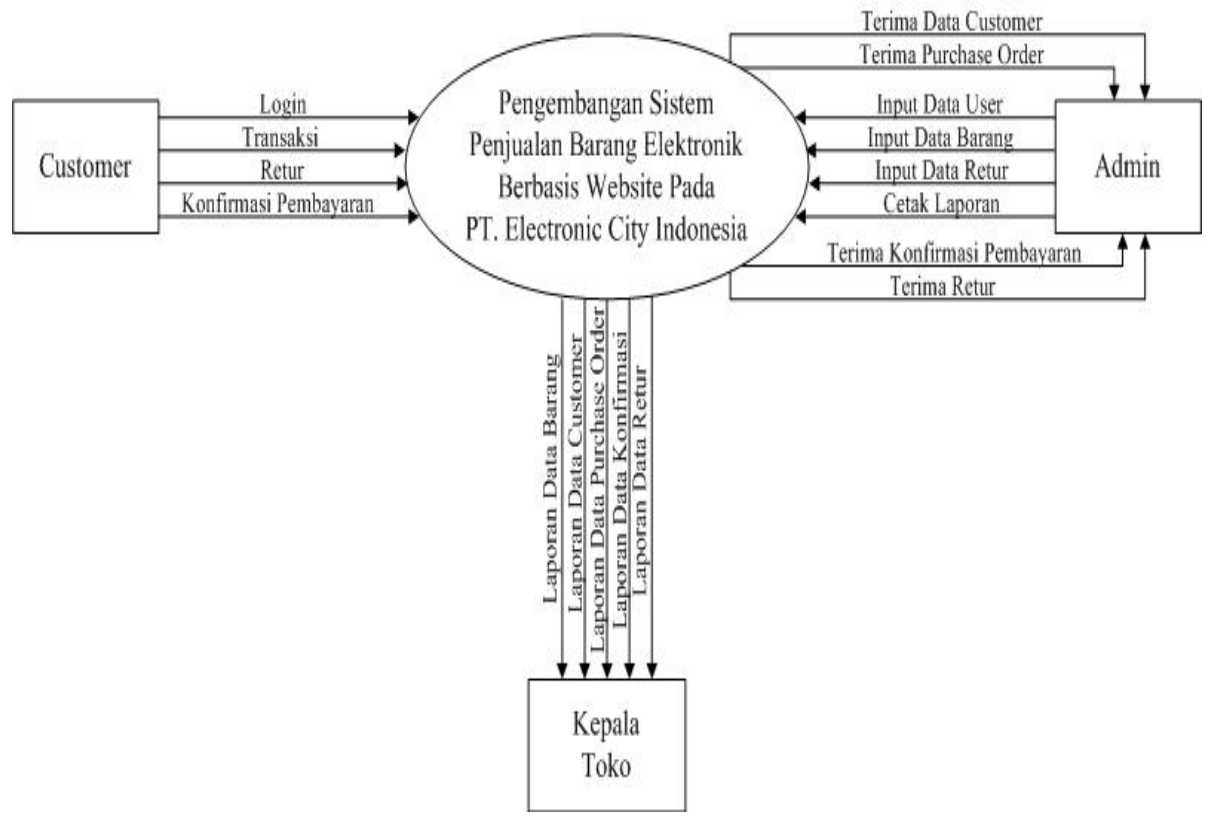

Gambar 2. DAD Sistem yang Diusulkan

Berikut ini adalah Entity Relationship Diagram yang Diusulkan

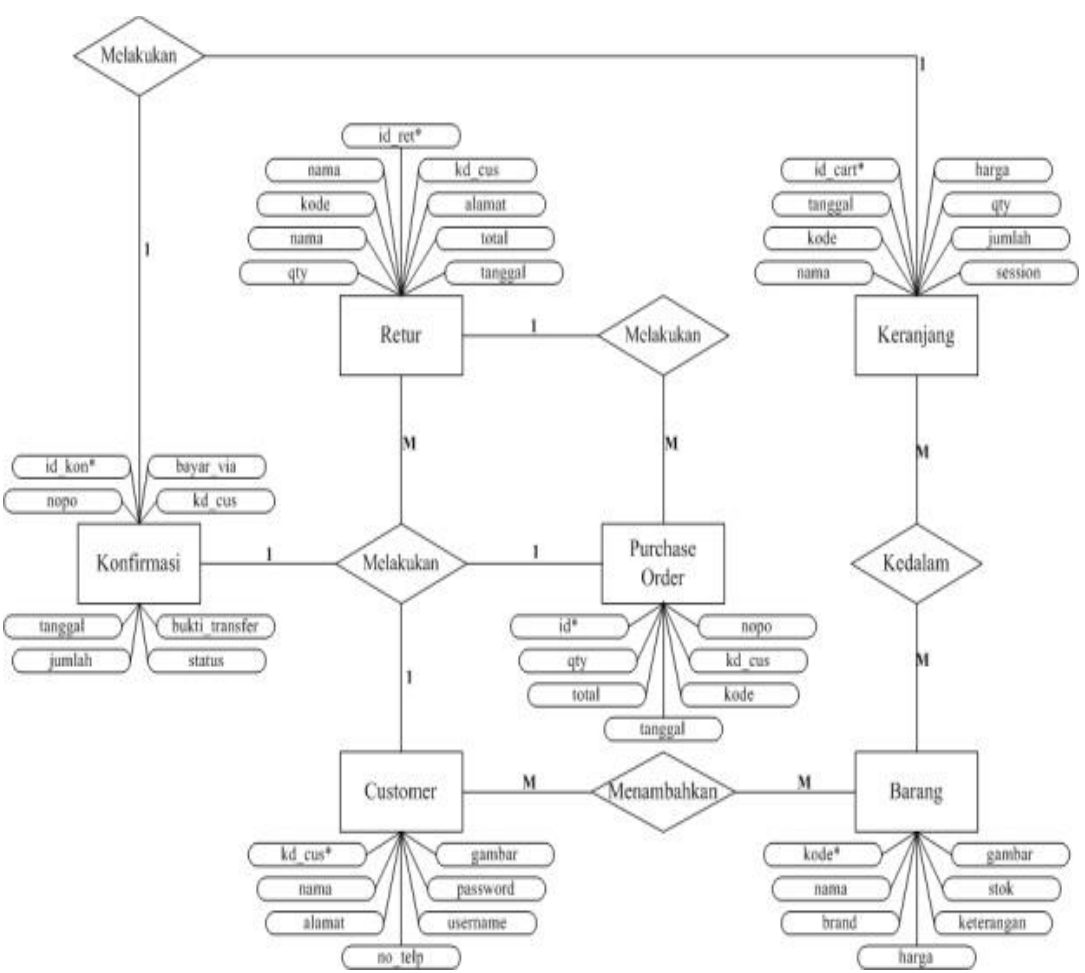

Gambar 3. Entity Relationship Diagram Sistem yang Diusulkan 
Tampilan Layar Sistem yang Diusulkan :

Tampilan Menu Login

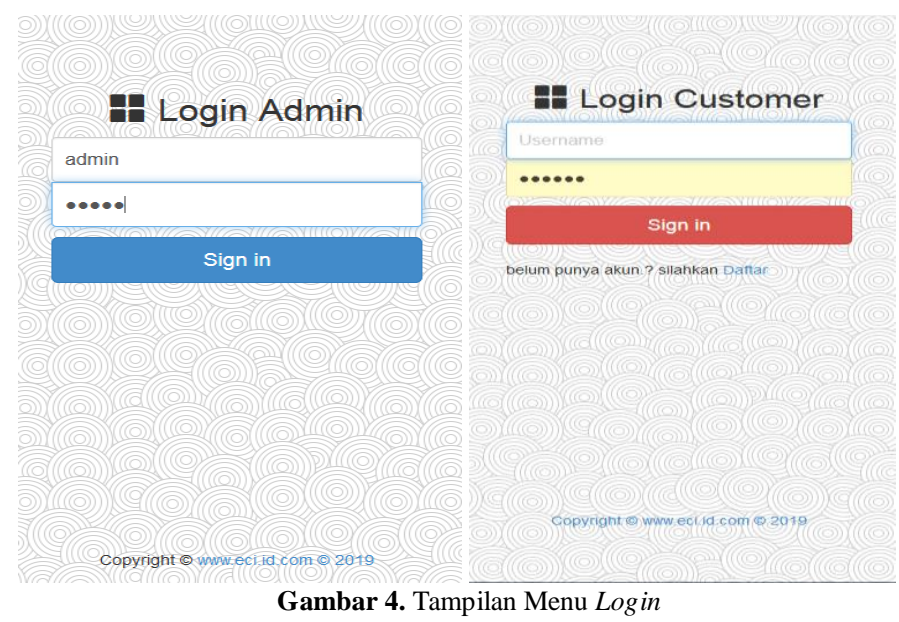

Pada saat user menjalankan aplikasi, maka akan muncul halaman Login. User diharuskan untuk mengisi username, password pada halaman Login agar dapat masuk ke dalam aplikasi penjualan barang elektronik

Tampilan Menu Utama Admin

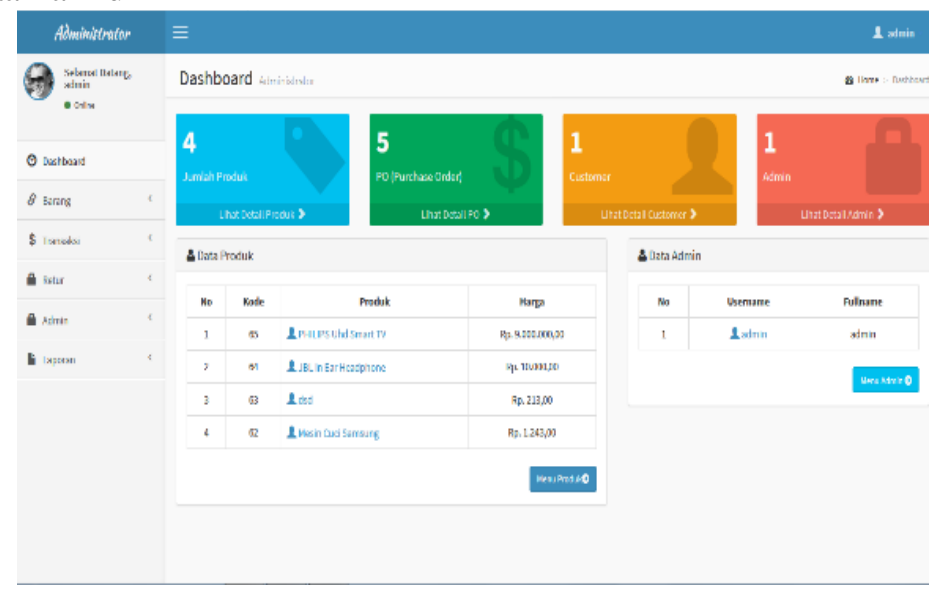

Gambar 5. Tampilan Menu Utama Admin

Pada halaman utama admin menampilkan pilihan menu dashboard data barang, data transaksi, data retur, data admin, dan laporan.

Tampilan Menu Utama Customer

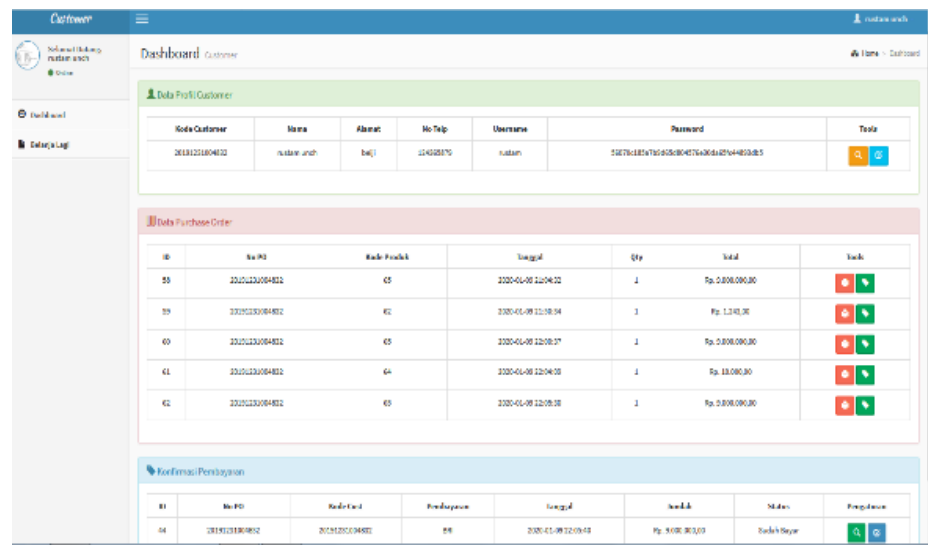

Gambar 6. Tampilan Menu Utama Customer 
Pada menu utama customer menampilkan dashboard data profil customer, data purchase order, dan konfirmasi pembayaran.

Tampilan Data Retur

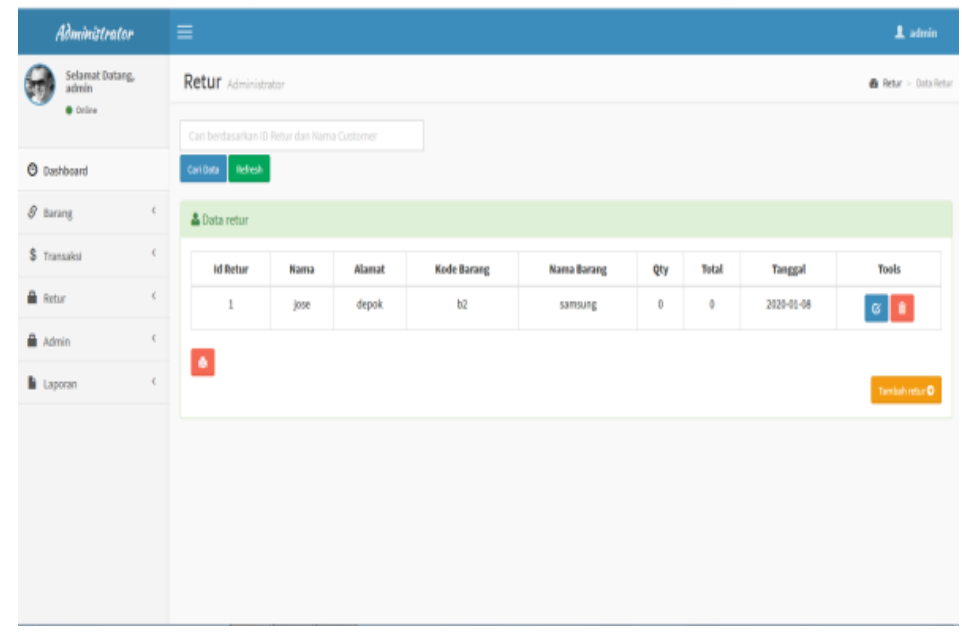

Gambar 7. Tampilan Data Retur

Tampilan halaman menu data retur yang berisi seluruh data retur yang sudah di Input. Pada halaman ini, ada beberapa fungsi diantaranya tambah data retur, ubah data retur, hapus data retur, dan cari data retur.

Tampilan Laporan Data Retur

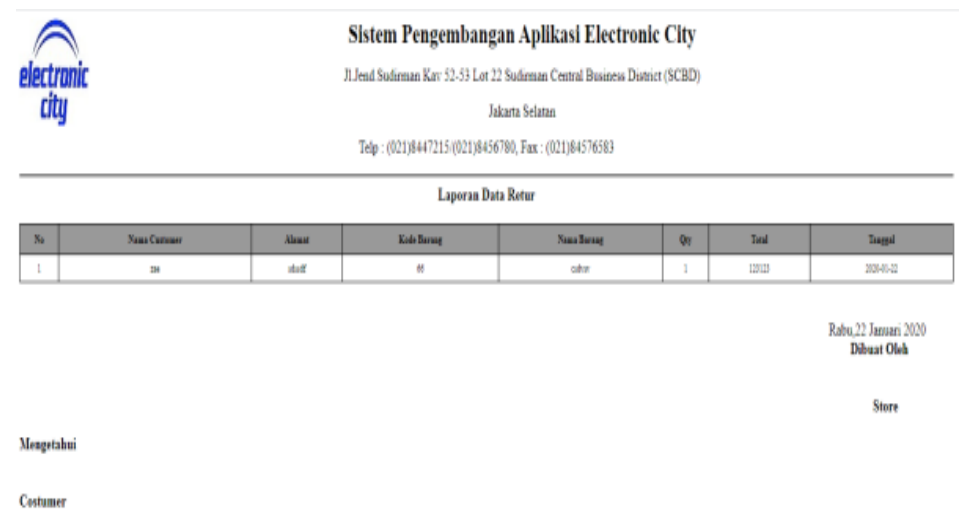

Gambar 8. Tampilan Laporan Data Retur

Tampilan Laporan Data Retur merupakan laporan data retur yang dapat di cetak untuk dapat digunakan sebagai laporan kepada kepala toko.

\section{SIMPULAN}

Dengan adanya Pengembangan Sistem Penjualan Barang Elektronik yaitu fitur retur, sehingga customer dapat dengan mudah untuk mengembalikan barang jika barang yang di beli tidak sesuai dengan yang diinginkan. Antarmuka yang sederhana dapat mempermudah user dalam mempelajari 
sistem ini. Nilai error Sistem Informasi penjualan ini adalah 0. Dan semua form dan tombol-tombol yang terdapat pada aplikasi dapat berjalan dengan baik. Hal ini berarti semua rancangan sistem yang dibuat berhasil diimplementasikan dengan baik.

\section{DAFTAR PUSTAKA}

Ahmad, S. (2013). Teori Belajar Dan Pembelajaran Di Sekolah Dasar. Biomass Chem Eng.

H, N. S. (2012). Android : Pemrograman Aplikasi Mobile Smartphone dan Tablet PC Berbasis Android (Edisi Revisi). In Android.

Indrajani, S. (2015). Perancangan Basis Data Dalam Allin1. Jakarta: PT. Elex Media Komputindo.

Krismiaji. (2015). Sistem Inormasi. In Sistem Informasi Akuntansi.

M Rudianto, A. (2011). Pemrograman Web Dinamis menggunakan PHP dan MySQL. Yogyakarta: C.V Andi Offset.

Majid, A. (2009). Perencanaan Pembelajaran. Bandung: PT. Remaja Rosda Karya.

Pressman, R. (2015). Software Engineering Seventh Edition. Metode Waterfall.

Puspitawati, L. dan S. A. (2010). Sistem Informasi Akuntansi. Yogyakarta: Graha Ilmu.

Raharjo, B. (2011). Membuat Database Menggunakan MySql. Bandung: Informatika.

Sulistiyowati, L. (2010). Panduan Praktis Memahami Analisis Laporan Keuangan. Jakarta: PT. Elex Media Komputindo. YM Kusuma, A. (2012). Menyelesaikan Website 30 Juta. Jakarta: Jasakom. 